\title{
Mechanical Properties of Al/BN Nanocomposites Fabricated by Planetary Ball Milling and Conventional Hot Extrusion
}

\author{
Reza Gostariani $^{1,2} \cdot$ Ramin Ebrahimi $^{1} \cdot$ Mohsen Asadi Asadabad ${ }^{2} \cdot$ Mohammad Hossein Paydar $^{1}$
}

Received: 28 March 2017/Revised: 8 May 2017/Published online: 29 August 2017

(C) The Chinese Society for Metals and Springer-Verlag GmbH Germany 2017

\begin{abstract}
In this study, Al matrix nanocomposites containing 1, 2 and 4 wt $\%$ nano-boron nitride were fabricated by mechanical milling and hot extrusion. The mechanical properties of all extruded samples were evaluated. Also, the morphology and microstructure of the milled composite powders were characterized using two types of electron microscope. The results showed that a high fraction of the boron nitride nanoparticles dissolved and formed a solid solution in $\mathrm{Al}$ matrix during the milling process. Through the process of solid solution formation, the work hardening rate of the composite powders increased. This led to a morphological change in the composite powders and resulted in equiaxed shape. The powder particle size also decreased after the milling process. By increasing boron nitride content within a range of 0-4 wt\% in the hot extruded samples, tensile stress increased from 212 to $333 \mathrm{MPa}$. The hardness of the nanocomposite samples including 1, 2 and $4 \mathrm{wt} \%$ boron nitride improved approximately 55, 70 and $90 \%$ in comparison with pure $\mathrm{Al}$, respectively.
\end{abstract}

KEY WORDS: AI/BN nanocomposite; Planetary ball milling; Hot extrusion; Mechanical properties; Microstructure

\section{Introduction}

Discontinuously reinforced aluminum (DRA) composites have several advantages: they are economic, light, easy to manufacture, and have higher specific stiffness and thermal conductivity. Therefore, they are mostly used in automotive and aerospace applications $[1,2]$. This group of the composites is reinforced by the particles, short fibers, and whiskers. The isotropic property of DRA composites is

Available online at http://link.springer.com/journal/40195

Reza Gostariani

rezagostariani@shirazu.ac.ir; rezagostariani@gmail.com

1 Department of Materials Science and Engineering, School of Engineering, Shiraz University, Shiraz, Iran

2 Materials and Nuclear Fuel Research School, Nuclear Science and Technology Research Institute, Tehran, Iran provided using different particles such as $\mathrm{Al}_{2} \mathrm{O}_{3}, \mathrm{~B}_{4} \mathrm{C}, \mathrm{SiC}$, etc. [3]. Among the ceramic particles, hexagonal boron nitride (h-BN) is a suitable candidate to be used as reinforcement in $\mathrm{Al}$ matrix composites due to its comprehensive physical and chemical properties resulting from low density (only $2.3 \mathrm{~g} / \mathrm{cm}^{3}$ ), high melting point temperature, high thermal conductivity and electrical resistivity [4-6]. On the other hand, h-BN is a soft ceramic particle, which is not stable in the Al system and is easily affected during high-energy ball milling [7, 8]. Planetary ball milling is a high-energy milling method involving cold welding, fracturing, and rewelding of composite powders. This milling process can lead to the decomposition of hexagonal boron nitride to boron and nitrogen elements and dissolution in $\mathrm{Al}$ matrix to form a solid solution $[4,9,10]$. By hot processing the mechanically milled $\mathrm{Al} / \mathrm{BN}$ composite powder at a relatively high temperature (hot extrusion or annealing), $\mathrm{AlN}$ and $\mathrm{AlB}_{2}$, as the in situ phases, are precipitated in the $\mathrm{Al}$ matrix of the formed bulk composite [7]. In situ phases 
with strong interfacial bonding, thermodynamic stability, and homogenous distribution in any matrix have a strong role in improving the mechanical properties of the composite [11-13].

Hexagonal boron nitride (h-BN) is hardly wetted by $\mathrm{Al}$ liquid at temperatures lower than $900{ }^{\circ} \mathrm{C}[4,7]$. Therefore, powder metallurgy is a preferable method compared to the casting process for fabrication of the $\mathrm{Al} / \mathrm{BN}$ composites. In addition, the hot extrusion process is a well-known method for producing bulk samples with full density from metallic powders without the need for sintering $[14,15]$. The mechanical properties of the extruded composites usually increase due to their refined microstructure, fewer voids and less segregation as well as the uniform distribution of their reinforcement and recrystallized grains [16-18]. Du et al. [7] fabricated an $\mathrm{Al} / 20 \mathrm{vol} \% \mathrm{BN}$ composite by planetary ball milling, hot pressing, and hot extrusion at $550{ }^{\circ} \mathrm{C}$. They found that the tensile strength of the composite increased from $135 \mathrm{MPa}$ of the monolithic Al to $230 \mathrm{MPa}$ due to the formation of $\mathrm{AlN}$ and $\mathrm{AlB}_{2}$ in situ phases in the extrusion process. In recent years, researchers have also evaluated the structure of $\mathrm{Al} / \mathrm{BN}$ composite powders and their solid solution formation during planetary ball milling $[4,9,10]$.

According to a collection of reports, extruded bulk Al/ BN nanocomposites have not been studied. In the present work, Al/BN nanocomposites with 1, 2, and $4 \mathrm{wt} \%$ boron nitride nanoparticles were fabricated by the planetary ball milling and hot extrusion processes. The positive effects of nano boron nitride reinforcement particles on the mechanical properties of the fabricated nanocomposites were investigated.

\section{Experimental Procedures}

Commercial pure $\mathrm{Al}$ powder with an average particle size of $45 \mu \mathrm{m}$ and irregular morphology (Fig. 1) was used as the matrix in the nanocomposite. Hexagonal boron nitride

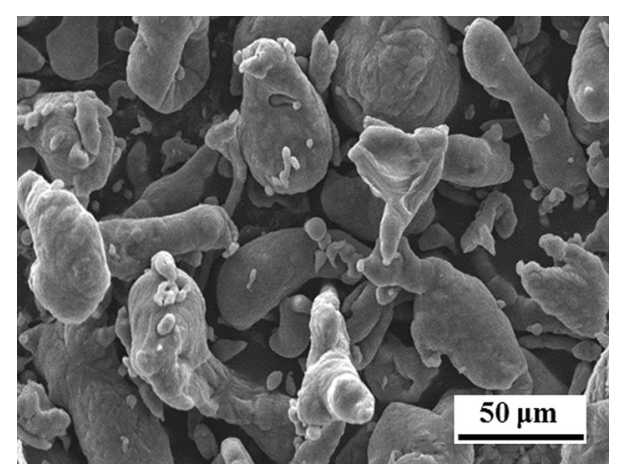

Fig. 1 SEM micrograph of unmilled pure Al powder nanoparticles (Lower Friction Company, with 99\% purity and an average size of $70 \mathrm{~nm}$ ) were utilized as reinforcement. Figure 2 shows the size and morphology of the boron nitride particles used.

$\mathrm{Al}$ matrix composite powders containing 1, 2 and $4 \mathrm{wt} \%$ nano-h-BN were prepared by planetary ball milling. For milling process, a mixture of $\mathrm{Al}$ and boron nitride powders with $1 \mathrm{wt} \%$ stearic acid (as the process control agent) was milled with a powder-to-ball weight ratio of 1:20. Planetary ball milling was performed for $300 \mathrm{~min}$ in an argon atmosphere and a rotation speed of $430 \mathrm{rpm}$. The same milling process was also carried out on pure $\mathrm{Al}$ powder for a reference sample.

The milled powder was annealed at $200{ }^{\circ} \mathrm{C}$ for $60 \mathrm{~min}$ to increase its compaction abilities. The resulting powder was consolidated using a cylindrical die, $35 \mathrm{~mm}$ in diameter, by applying $190 \mathrm{MPa}$ uniaxial stress to obtain coldpressed billets. After heating the billets at $580{ }^{\circ} \mathrm{C}$ for $45 \mathrm{~min}$, they were extruded to fabricate the final dense rod billets, with a diameter of $10 \mathrm{~mm}$ (Fig. 3). The hot extrusion process was carried out with 12:1 extrusion ratio through a die with a die angle of $43^{\circ}$, which was designed by Avitzur relations [19]. For comparison, milled and unmilled pure Al bulk specimens were prepared by the same extrusion process to be used as the reference samples.

The phase evaluation of an Al/BN nanocomposite was investigated by X-ray diffraction (Philips PW 1800 with $\mathrm{Cu}$ $K \alpha$ radiation). The composition of $\mathrm{Al} / 15 \mathrm{wt} \% \mathrm{BN}$ was selected to measure the change in the amount of the created new phases. Therefore, $\mathrm{Al} / 15 \mathrm{wt} \% \mathrm{BN}$ nanocomposite powder was fabricated by the same milling conditions, cold compaction, and sintering at $580{ }^{\circ} \mathrm{C}$ for $45 \mathrm{~min}$ (the applied extrusion temperature for the extruded samples).

The morphologies of the pure $\mathrm{Al}$ and boron nitride powders as well as the milled powders were examined by a scanning electron microscope (Philips XL 30). A transmission electron microscope (TEM, Philips $100 \mathrm{kV}$ ) was also used to observe the boron nitride nanoparticles and the microstructure of the milled composite powders. The microstructure of the bulk extruded sample was studied in the direction of extrusion using TEM (JEOL JEM-2100F) by an operating voltage of $200 \mathrm{kV}$. A thin-foil specimen with a thickness of $100 \mu \mathrm{m}$ was made by mechanical polishing. The thin foil was prepared by using a twin-jet polishing TenuPol-5 facility (Struers Co., Ltd.) in an electrolyte solution of $20 \mathrm{vol} \% \mathrm{HClO}_{4}$ and $80 \mathrm{vol} \%$ ethanol with a voltage of $35 \mathrm{~V}$ at $-20{ }^{\circ} \mathrm{C}$. Finally, the final thinning was performed by ion beam using a GATAN 691 precision ion polishing system (PIPS). The density of the extruded samples was examined by the Archimedes test.

Tensile, compression, and hardness tests were carried out in order to evaluate the mechanical properties of the extruded samples. The cylindrical tensile samples, $6 \mathrm{~mm}$ in 

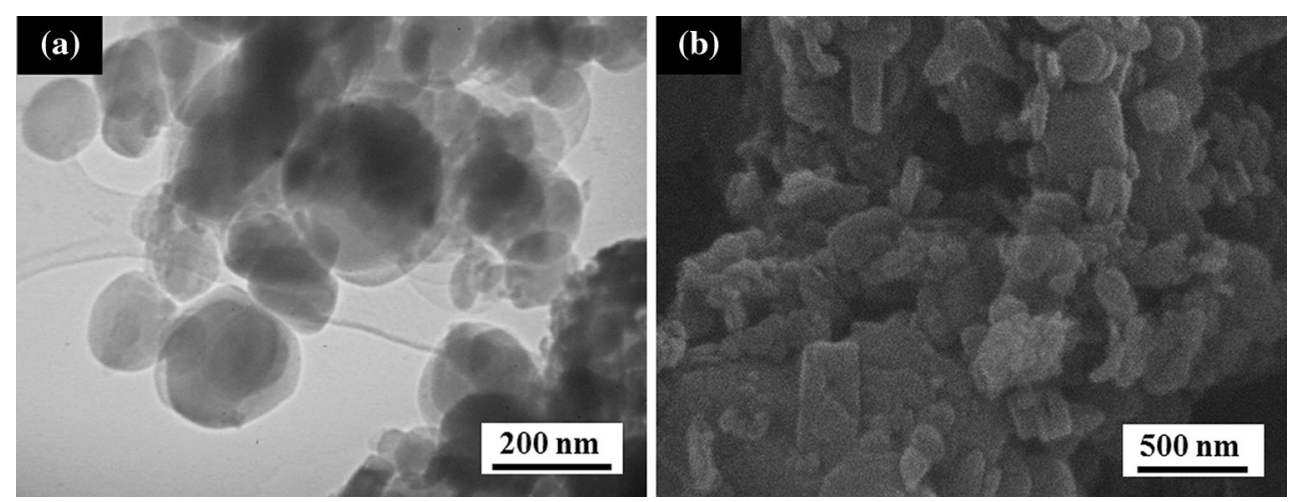

Fig. 2 TEM a, SEM $\mathbf{b}$ images of boron nitride nanoparticles

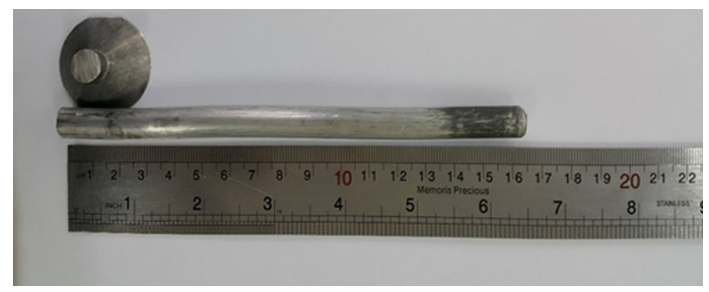

Fig. 3 Photograph of extruded rod billet

diameter and $30 \mathrm{~mm}$ in gage length, were machined according to ASTM E8. For the compression test, cylindrical samples with a height of $13.5 \mathrm{~mm}$ and a diameter of $9 \mathrm{~mm}$ were prepared. The tension and compression tests were conducted along the extrusion direction at room temperature and constant ram speed of $0.5 \mathrm{~mm} / \mathrm{min}$. A Teflon band was used as the lubricant in the compression test. To investigate hardness, both macro- and microhardness values were measured by the Vickers method under $10 \mathrm{~kg}$ and $100 \mathrm{~g}$ applied loads, respectively.

\section{Results}

\subsection{Structural Evaluation}

Figure 4 shows the change in pure $\mathrm{Al}$ and composite powder morphologies after 300-min planetary ball milling. As can be seen in Fig. 4a, the morphology of the pure Al powder changed to a flaky shape and coarse agglomerated particles were formed during the milling process. On the other hand, the presence of boron nitride nanoparticles accelerated the morphological change of the composite powders into an equiaxed shape and caused the decrease in the size of the particles (Fig. $4 b-d$ ).

Figure 5 displays the TEM micrograph and corresponding selected area diffraction (SAD) patterns of the $\mathrm{Al} / 4$ wt\% BN nanocomposite powder. As can be seen, the $\mathrm{Al}$ phase appeared as a continuous ring shape in the SAD pattern and a structure with nanocrystallite was developed in the Al matrix as a result of high-energy milling. Although the boron nitride nanoparticles can be observed in the microstructure, a high fraction of boron nitride was dissolved in the Al matrix and a solid solution formed.

Figure 6 shows the TEM micrograph of the extruded Al/ $1 \mathrm{wt} \% \mathrm{BN}$ nanocomposite. The microstructure of this nanocomposite after extrusion shows recrystallized $\mathrm{Al}$ nanograins/ultrafine grains. Furthermore, Al grains kept their nanosize/submicron size and no important grain growth occurs after hot extrusion.

\subsection{Phase Evaluation}

Figure 7 demonstrates the XRD patterns of unmilled, mechanically milled, and sintered Al/15 wt\% BN composite powders. As can be seen, the peaks of the BN disappeared after 300-min milling (Fig. 7b). On the other hand, according to the XRD pattern of the samples in Fig. 7c, $\mathrm{AlN}$ and $\mathrm{AlB}_{2}$ were the in situ phases and formed by sintering the composite milled powders. Therefore, based on the XRD result for the $\mathrm{Al} / 15 \mathrm{wt} \% \mathrm{BN}$ treated with the same milling and sintering conditions used for the extruded samples, it can be surmised that the solid-state reaction might occur for the formation of $\mathrm{AlN}$ and $\mathrm{AlB}_{2}$ in the hot extrusion process at $580{ }^{\circ} \mathrm{C}$ in the present work. Hence, $\mathrm{AlN}$ and $\mathrm{AlB}_{2}$ can be considered as the in situ phases formed in the extruded samples with a lower content of $1-4 \mathrm{wt} \%$ boron nitride particles.

\subsection{Relative Density Measurement}

The relative density change across the extruded samples with different compositions is shown in Fig. 8. As can be seen, the relative density of each sample is higher than $99 \%$ and is close to theoretical quantities. Hence, the extrusion process is an effective method to eliminate porosity and reach full density in the consolidation of composite powders. However, as can be seen, the densities gradually 

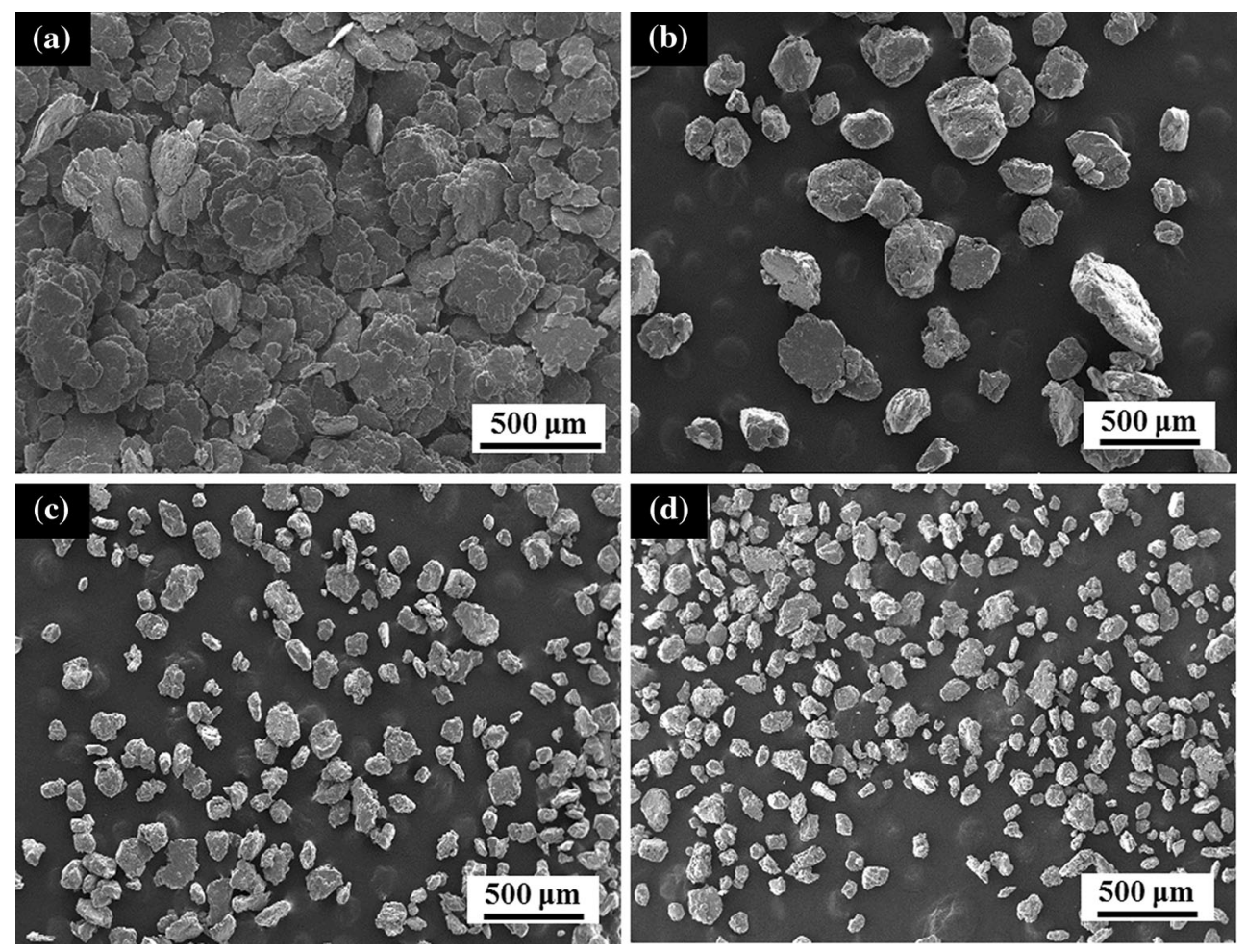

Fig. 4 Morphologies of pure $\mathrm{Al}$ a, $\mathrm{Al} / 1 \mathrm{wt} \% \mathrm{BN} \mathbf{b}, \mathrm{Al} / 2 \mathrm{wt} \% \mathrm{BN}$ c, $\mathrm{Al} / 4 \mathrm{wt} \% \mathrm{BN}$ d powders after 300-min milling

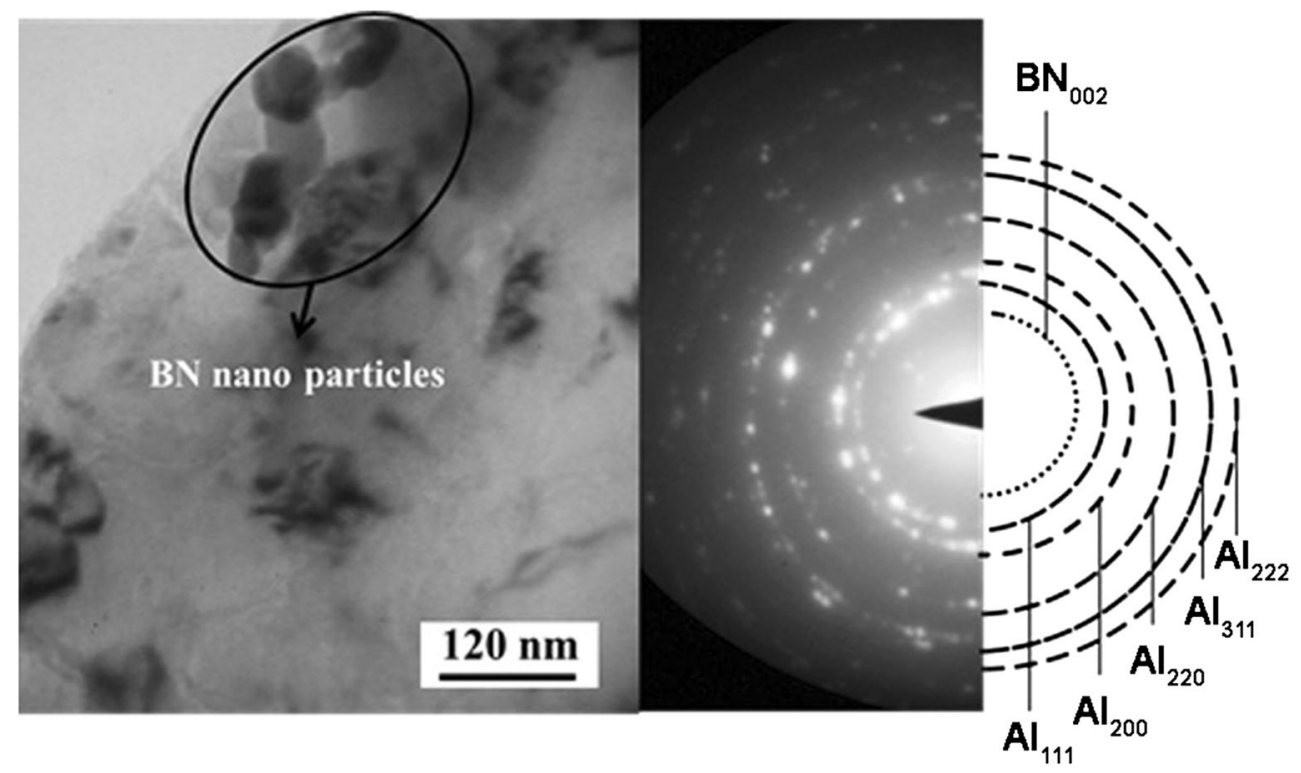

Fig. 5 TEM micrograph with SAD pattern of $\mathrm{Al} / 4$ wt $\%$ BN composite powders after 300-min milling

decrease with the increase in the amount of boron nitride. In fact, during the ball milling process, the work hardening rate of the composite powders increases with the increase in the amount of boron nitride. Therefore, compressibility decreases and full density cannot be reached through the same hot extrusion process.

\subsection{Mechanical Properties}

The engineering stress-strain tensile curves for all the extruded samples including consolidated unmilled and milled pure $\mathrm{Al}$ powders and $\mathrm{Al} / \mathrm{BN}$ nanocomposite powders with different compositions are shown in Fig. 9. The 


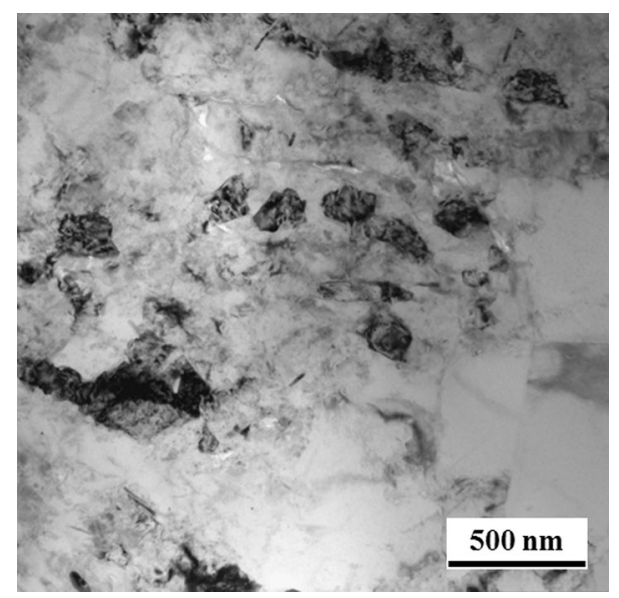

Fig. 6 TEM micrograph of extruded $\mathrm{Al} / 1 \mathrm{wt} \% \mathrm{BN}$ nanocomposite

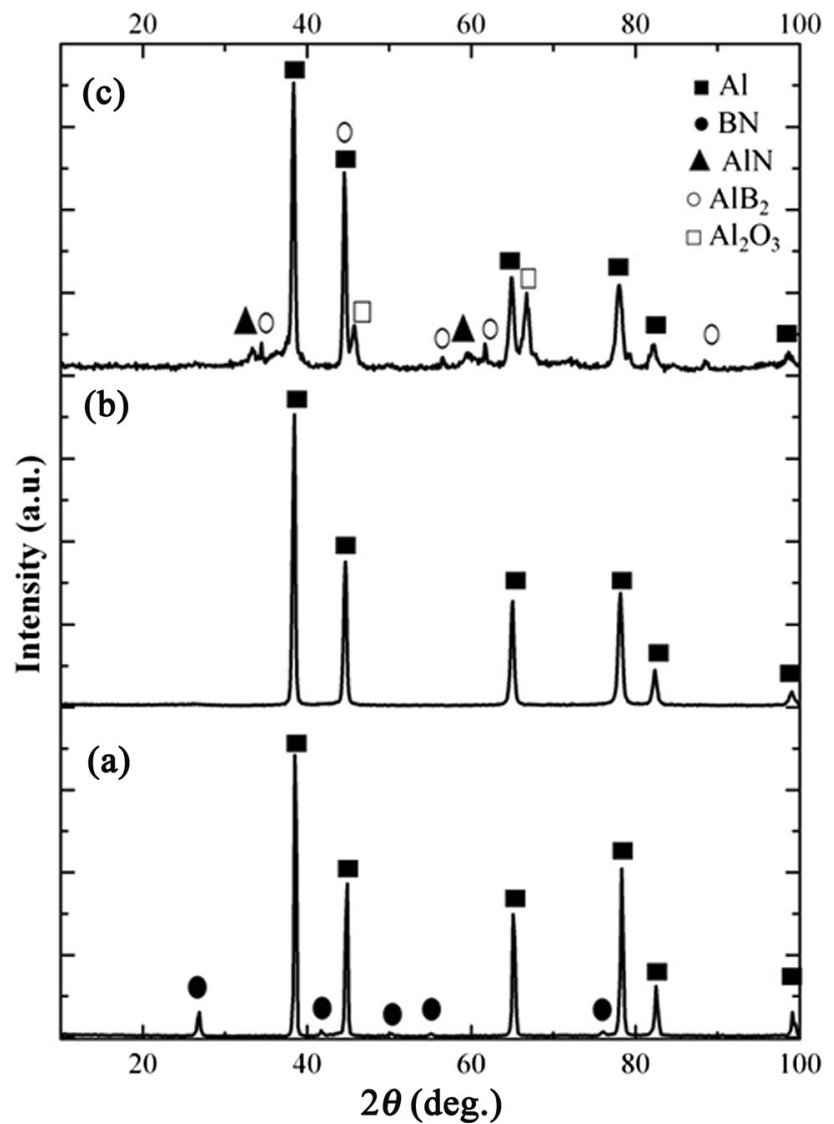

Fig. 7 XRD patterns of $\mathrm{Al} / 15 \mathrm{wt} \% \mathrm{BN}$ nanocomposite under different conditions: a unmilling composite powders; b 300-min milling; c cold compaction and sintering

tensile stress and elongation of the consolidated unmilled pure $\mathrm{Al}$ powders were recorded as $104 \mathrm{MPa}$ and $26 \%$, respectively. After milling the pure $\mathrm{Al}$, its tensile stress increased to about $212 \mathrm{MPa}$ and its elongation decreased to $15 \%$. The tensile stress value of the $\mathrm{Al} / 1 \mathrm{wt} \% \mathrm{BN}$ composite $(297 \mathrm{MPa})$ increased 40 and $185 \%$ compared to

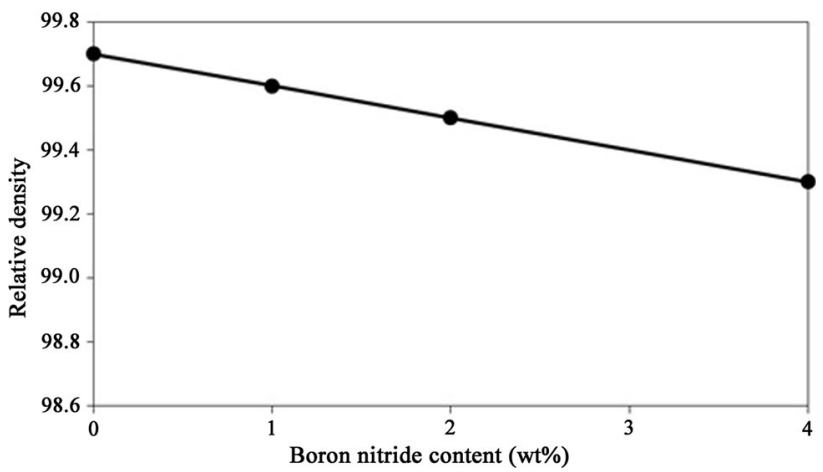

Fig. 8 Relative density changes of extruded samples as a function of boron nitride content

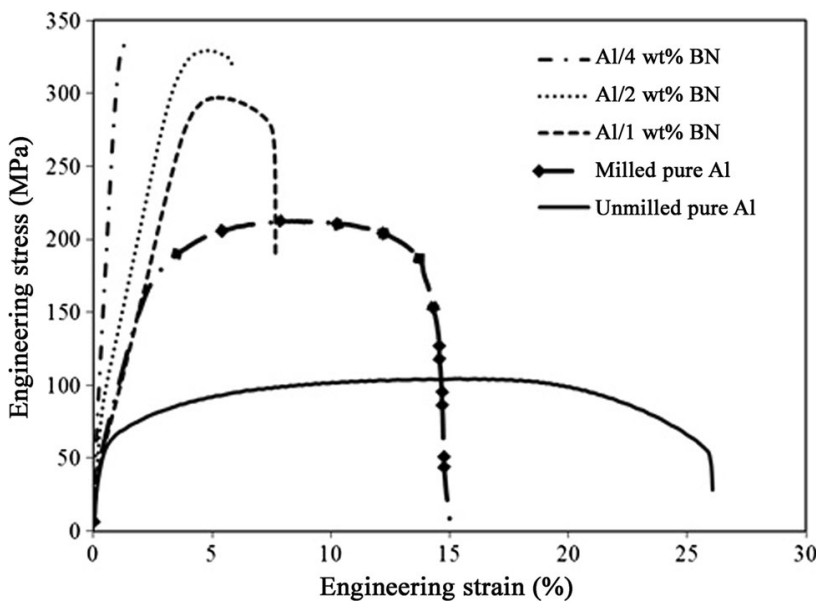

Fig. 9 Engineering stress-strain tensile curves for extruded unmilled pure $\mathrm{Al}$, milled pure $\mathrm{Al}$ and $\mathrm{Al} / \mathrm{BN}$ nanocomposites

those of milled and unmilled pure $\mathrm{Al}$, respectively. By increasing the boron nitride content up to $2 \mathrm{wt} \%$, the tensile stress of the nanocomposite increased to about $330 \mathrm{MPa}$, which is 55\% higher than that of the milled pure Al. On the other hand, the tensile stress of the nanocomposite including $4 \mathrm{wt} \%$ boron nitride slightly increased compared to that of $\mathrm{Al} / 2 \mathrm{wt} \% \mathrm{BN}$ nanocomposite and reached to $333 \mathrm{MPa}$. However, the higher strength of the nanocomposites is gained at the cost of decrease in ductility. The ductility of the nanocomposites including 1,2 , and $4 \mathrm{wt} \% \mathrm{BN}$ decreased to about 8, 6, and $1.3 \%$, respectively.

The quality index (QI) is a parameter to qualify the tensile properties of metallic samples [20]:

$\mathrm{QI}=\mathrm{UTS}(\mathrm{MPa})+150 \times \log ($ Elongation, \%).

The QI parameter of all the extruded samples was measured, and their values are given in Table 1 . The quality index is a function of ultimate strength and elongation. The quality index of metallic materials increases by improving their tensile properties [21]. The 
Table 1 Quality index (QI) information from the tensile test of extruded samples

\begin{tabular}{llll}
\hline Material & UTS (MPa) & Elongation $(\%)$ & QI (MPa) \\
\hline Unmilled pure Al & 104 & 26.0 & 316 \\
Milled pure Al & 212 & 15.0 & 388 \\
Al $/ 1$ wt\% BN nanocomposite & 297 & 7.7 & 430 \\
Al $/ 2$ wt\% BN nanocomposite & 330 & 5.8 & 444 \\
Al/4 wt\% BN nanocomposite & 333 & 1.4 & 355 \\
\hline
\end{tabular}

results show that $\mathrm{Al} / 2 \mathrm{wt} \% \mathrm{BN}$ and $\mathrm{Al} / 1 \mathrm{wt} \% \mathrm{BN}$ have the highest quality index values of 444 and $430 \mathrm{MPa}$, respectively. As can be seen, the quality index values of these two composites are comparable despite their different $\mathrm{BN}$ contents. Therefore, the composite with a lower amount of reinforcement $(\mathrm{Al} / 1 \mathrm{wt} \% \mathrm{BN})$ can be selected as the best composition for engineering applications. On the other hand, the quality index of the composite with $4 \mathrm{wt} \%$ boron nitride decreased.

The tensile strength results of $\mathrm{Al} / \mathrm{BN}$ composites fabricated by different methods and presented in the literature along with the tensile strength results obtained in the present work are listed in Table 2. As can be seen, powder metallurgy methods using high-energy milling for powder preparation have a remarkable effect on increasing tensile strength. The poor wettability of $\mathrm{BN}$ particles in $\mathrm{Al}$ liquid and the poor bonding between $\mathrm{Al}$ and $\mathrm{BN}$ particles in the wet mixing method have led to the exclusion of casting and conventional wet mixing methods for the fabrication of $\mathrm{Al} /$ $\mathrm{BN}$ composites. Although the tensile strength of a micronsized Al/BN composite fabricated by high-energy milling and spark plasma sintering [22] is better than that of its matrix, the nanosize of boron nitride particles leads to the reduction of their use as reinforcement agents in composites. For instance, in this study, the tensile strength of the nanocomposite with a minimum content of boron nitride nanoparticles ( $1 \mathrm{wt} \% \mathrm{BN}$ ) increased $40 \%$ compared to that of the matrix (milled pure $\mathrm{Al}$ ).

Figure 10 shows the compressive true stress-strain curves of the extruded samples. As can be seen, the compressive strength values of the nanocomposite samples are significantly higher than those of the unmilled and milled pure Al. Due to the use of nanoparticles, even the minimum reinforcement amount $(1 \mathrm{wt} \%)$ can be very effective in improving the mechanical properties of nanocomposites.

The similar macro- and microhardness values of each extruded samples are presented in Fig. 11. Based on the data presented in this figure, it can be concluded that after the extrusion process, all samples fabricated in the present work have uniform hardness. The hardness of the extruded milled pure Al sample is significantly higher than that of the sample fabricated using unmilled pure $\mathrm{Al}$ powder. By increasing boron nitride content, hardness values also increased remarkably. The comparison of the average

Table 2 Comparing tensile strengths of Al/BN composites in the literature with those of the present study

\begin{tabular}{|c|c|c|c|c|c|}
\hline References & Composition & Powder preparation & Fabrication technique & $\begin{array}{l}\text { Tensile } \\
\text { strength } \\
(\mathrm{MPa})\end{array}$ & $\begin{array}{l}\text { Compared } \\
\text { to matrix } \\
(\%)\end{array}$ \\
\hline [7] & $\mathrm{Al} / 20$ vol\% $\mathrm{BN}$ & $\begin{array}{l}\text { High-energy ball milling } \\
\quad(20 \mathrm{~h})\end{array}$ & $\begin{array}{l}\text { Hot press }\left(600{ }^{\circ} \mathrm{C}\right) \text { and hot extrusion } \\
\quad\left(550^{\circ} \mathrm{C}\right)\end{array}$ & 230 & 70 \\
\hline \multirow[t]{3}{*}{ [23] } & $\mathrm{A} 12124 / 5 \mathrm{wt} \% \mathrm{BN}$ & \multirow[t]{3}{*}{ Wet mixing } & \multirow{3}{*}{$\begin{array}{l}\text { Cold compaction and hot extrusion } \\
\left(500^{\circ} \mathrm{C}\right)\end{array}$} & 377 & -9 \\
\hline & $\mathrm{A} 12124 / 10 \mathrm{wt} \% \mathrm{BN}$ & & & 311 & -25 \\
\hline & $\mathrm{A} 12124 / 15 \mathrm{wt} \% \mathrm{BN}$ & & & 213 & -48 \\
\hline \multirow[t]{2}{*}{ [5] } & $\mathrm{Al} / \mathrm{Mg} / 5 \mathrm{vol} \% \mathrm{BN}$ & \multirow[t]{2}{*}{-} & \multirow[t]{2}{*}{ Pressure less infiltration method } & 390 & 15 \\
\hline & $\mathrm{Al} / \mathrm{Mg} / 7.5$ vol\% BN & & & 416 & 23 \\
\hline$[24]$ & $\begin{array}{r}\mathrm{Al} / 4.5 \mathrm{wt} \% \mathrm{BN} \\
\text { nanoparticles }\end{array}$ & Wet mixing by ultrasonic & Spark plasma sintering & 150 & 50 \\
\hline$[22]$ & $\begin{array}{l}\mathrm{Al} / 5 \mathrm{wt} \% \mathrm{BN} \\
\text { microparticles }\end{array}$ & High-energy ball milling $(2 \mathrm{~h})$ & Spark plasma sintering & 385 & 130 \\
\hline This study & $\begin{array}{l}\mathrm{Al} / 1 \mathrm{wt} \% \mathrm{BN} \\
\text { nanoparticles }\end{array}$ & $\begin{array}{l}\text { High-energy ball milling } \\
\text { (300 min) }\end{array}$ & $\begin{array}{l}\text { Cold compaction and hot extrusion } \\
\qquad\left(550{ }^{\circ} \mathrm{C}\right)\end{array}$ & 297 & 40 \\
\hline
\end{tabular}




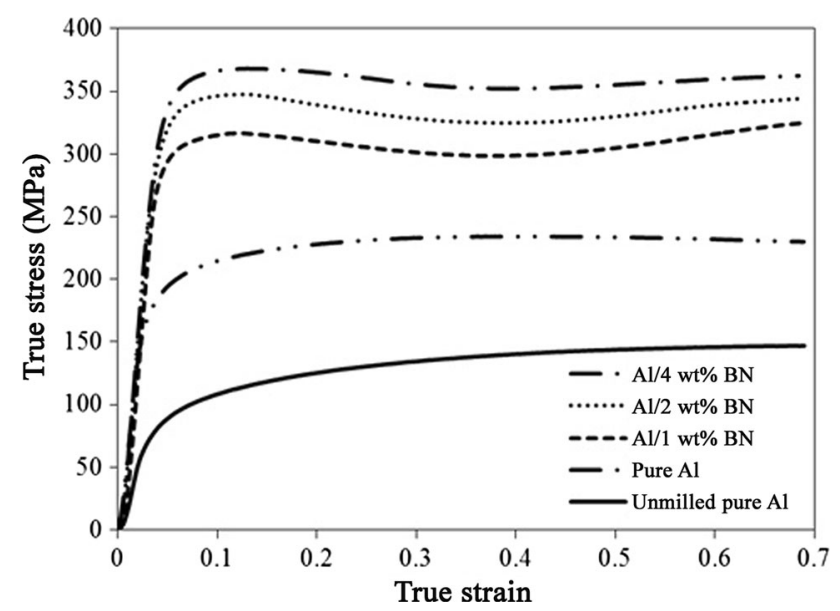

Fig. 10 True stress-strain compression curves of extruded samples

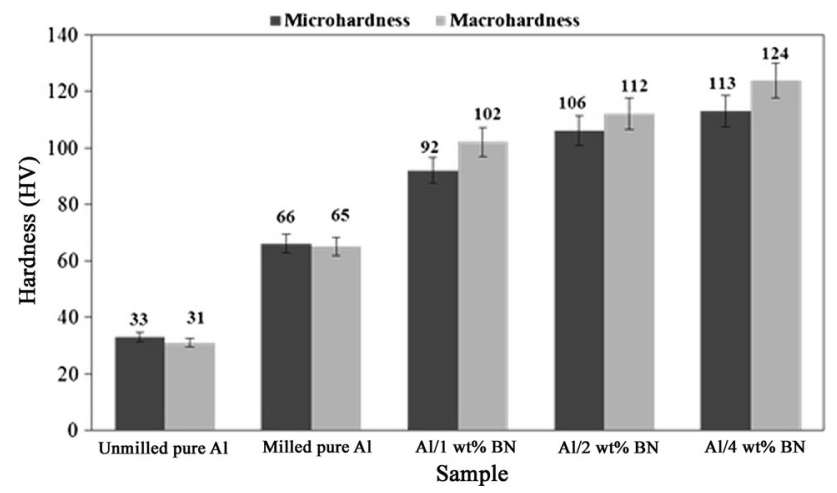

Fig. 11 Micro- and macrohardness of extruded nanocomposite samples

macro- and microhardness values of the nanocomposite samples including 1, 2, and $4 \mathrm{wt} \%$ boron nitride with those of milled pure $\mathrm{Al}$ of the same conditions showed increased values of about 55,70 , and $90 \%$, respectively.

\section{Discussion}

\subsection{Structural Evaluation}

During the high-energy milling process, repeated cold welding, fracturing, and rewelding, powder morphology change significantly [25]. However, in this study, it seems that cold welding is the dominant mechanism in the milling process of pure Al powders (Fig. 4a). On the other hand, the role of the boron nitride as a soft particle in the milling process is different from those of hard reinforcement particles such as $\mathrm{Al}_{2} \mathrm{O}_{3}, \mathrm{~B}_{4} \mathrm{C}$, and $\mathrm{SiC}$. Hard and non-deformable particles usually increase dislocation density in composite powders during high-energy ball milling and accelerate grain refinement [25]. However, h-BN is a soft ceramic material which acts as a process control agent
(PCA) and prevents the agglomeration of $\mathrm{Al}$ particles in the milling process. In addition, the boron nitride with weak Van der Waals bonding between its layers is unstable in the mechanical milling of the Al/BN system [7]. It has been suggested that $\mathrm{BN}$ decomposes to boron and nitrogen atoms and then dissolves in $\mathrm{Al}$ matrix [4, 9, 10]. This solid solution formation increases work hardening rate and causes the fracture mechanism to prevail in the milling process. That is why the morphology of our composite powders appeared in equiaxed shape and grain refinement occurred in the milling condition (Fig. 4b-d).

According to the TEM micrograph of the extruded specimen in Fig. 6, the boron nitride particles were not observed in the microstructure. It can be concluded that the boron nitride disappeared during nanocomposite fabrication. In other words, the boron nitride was dissolved in $\mathrm{Al}$ matrix during the high-energy milling process and an AlBN solid solution was formed. In addition, the high plastic deformation in the milling results in formation of dislocation networks and subgrains in the microstructure of the powder [17]. This phenomenon led to the development of the nanostructure in the composite particles, which resulted in a ring shape in their SAD pattern as can be seen in Fig. 5. On the other hand, the refined composite powder microstructure remained in the form of ultrafine grains/nanograins in the bulk microstructure after carrying out the hot extrusion process (Fig. 6). Therefore, it is obvious that the effect of $\mathrm{BN}$ in the nanocomposite prevented the movement of grain boundaries and led to the stability of the ultrafine structure/nanostructure under the influence of the high temperature of the extrusion process.

\subsection{Phase Evaluation}

$\mathrm{Al} / \mathrm{BN}$ composite powders can be categorized as ductile/ductile systems in the milling process. In such systems, the lamella structure is formed in the initial stage of the milling process [26]. In this study, in the milling process, the boron nitride decomposes to boron and nitrogen and dissolves in $\mathrm{Al}$ matrix. This is why the XRD peaks of $\mathrm{BN}$ disappeared after 300-min milling (Fig. 7b). In the next step, when the milled powder is exposed to high temperature, the in situ $\mathrm{AlN}$ and $\mathrm{AlB}_{2}$ nanophases are formed $[4,7,9,24]$. These in situ phases (Fig. 7c) were produced according to the following solid-state reaction [7]:

$3 \mathrm{Al}+2 \mathrm{BN}=2 \mathrm{AlN}+\mathrm{AlB}_{2}$.

The Gibbs free energy of the above reaction is negative across the temperature range and is thermodynamically feasible [24]. In addition, the mechanical milling process facilitates the solid-state reaction [10]. In this study, a high fraction of the boron nitride was dissolved in $\mathrm{Al}$ matrix after 300-min ball milling and a solid solution was formed. 
The solid solution formation occurred in a short time during the milling process due to the use of nanosize boron nitride particles.

\subsection{Mechanical Properties}

The mechanical properties of the extruded Al/BN nanocomposites were enhanced by grain refinement, solid solution hardening, and in situ formation and dispersion of the $\mathrm{AlN}$ and $\mathrm{AlB}_{2}$ phases in the $\mathrm{Al}$ metallic matrix. According to the Hall-Petch equation, material yield strength is affected by grain refinement [27]. Therefore, as a result of decreasing nanocomposite grain to nanometer size (Fig. 6) and having a high lattice microstrain in a nanocrystalline structure, which is a characteristic phenomenon in high-energy ball milling, an increase in the yield strength of the milled samples is expected. The high volume of the grain boundaries in milled nanostructures acts as a barrier, which prevents dislocation movement and enhances tensile strength [3, 28, 29]. As can be seen in Fig. 9, grain refinement is the reason for increase in nanocomposite and milled pure $\mathrm{Al}$ strengths. On the other hand, compared to other ceramic particles, hexagonal boron nitride particles have a special role in improving the mechanical properties of $\mathrm{Al}$ matrix composites. The mechanical properties of the $\mathrm{Al} / \mathrm{BN}$ composite strongly depend on the method used for the preparation of the composite powder. Boron nitride is a soft ceramic particle, which alone cannot improve the mechanical properties of the composites by the Orowan mechanism [7]. In addition, this particle has poor bonding with $\mathrm{Al}$ when used in conventional methods for powder preparation [7] such as wet attrition or wet mixing. As can be seen in Table 2, the mechanical properties of the $\mathrm{Al} / \mathrm{BN}$ composite, which was fabricated by wet attrition and hot extrusion, decreased compared with those of its own matrix [23]. On the other hand, the mechanical properties of $\mathrm{Al} / \mathrm{BN}$ composites are increased when high-energy ball milling is used for composite powder preparation. The main reason for the grain refinement of $\mathrm{Al} / \mathrm{BN}$ composite powder can be the decomposition of hexagonal boron nitride to boron and nitrogen during the high-energy ball milling process [4]. The high-energy milling increases defects in the $\mathrm{Al}$ matrix; subsequently, the boron and nitrogen atoms created by the decomposition of the boron nitride are diffused in the matrix and dissolved resulting in a solid solution [7]. Furthermore, AlN and $\mathrm{AlB}_{2}$ as the in situ phases are generated during the heating process $[4,7,9,10]$. In this study, therefore, the dispersed in situ $\mathrm{AlN}$ and $\mathrm{AlB}_{2}$ phases, which were characterized using XRD in $\mathrm{Al} / 15 \mathrm{wt} \% \mathrm{BN}$ composite (Fig. 7), are important agents in improving the tensile strength of $\mathrm{Al} / \mathrm{BN}$ nanocomposites compared to milled pure Al. The in situ formed $\mathrm{AlN}$ and $\mathrm{AlB}_{2}$ phases are hard ceramic components, which cause matrix distortion hindering dislocation motion, the occurrence of which is collectively known as the Orowan mechanism. According to this mechanism, a decrease in reinforcement particle distance leads to an increase in the strength of composite materials according to the following equation $[3,27,30]$ :

$\tau=G b / \lambda$

where $\tau, G$ and $b$ are shear strength, shear modulus and Burger's vector, respectively, and $\lambda$ is the distance between the reinforcement particles. By decreasing $\lambda$, the shear strength increases. Therefore, the in situ $\mathrm{AlN}$ and $\mathrm{AlB}_{2}$ particles with nanometric size and nanometric distance $\lambda$ [7] are main reason for increasing strength in $\mathrm{Al} / \mathrm{BN}$ nanocomposites. Moreover, the in situ phases formed in the composite samples prevented grain growth in hot extrusion process and led to grain refinement in the composite (Fig. 6).

As can be seen in Fig. 9, ductility of the extruded samples decreased when mechanical strength increased. One of the most important reasons for the lower ductility of nanocrystalline materials is the low work hardening rate of this material in plastic deformation [17]. In fact, in very fine grains, grain boundaries act as a sink for the annihilation of dislocations and the conventional mechanisms of dislocation accumulation fail because the boundaries are very close to each other [31].

As can be seen in Table 1, the quality index of the extruded samples was improved by increasing boron nitride content up to $2 \mathrm{wt} \%$ and decreased for $\mathrm{Al} / 4 \mathrm{wt} \% \mathrm{BN}$. This suggests that the QI parameter is more sensitive to tensile ductility than to tensile strength [21]. Therefore, the considerable deterioration in nanocomposite ductility especially for the samples including $4 \mathrm{wt} \% \mathrm{BN}$ decreases the QI parameter. Hence, a lower content of boron nitride nanoparticles in composite materials is more applicable for engineering purposes.

In this study, although crystallite refining in the milling process increased hardness, the dispersion of the in situ AlN and $\mathrm{AlB}_{2}$ phases also played an effective role in promoting hardness in nanocomposite samples (Fig. 11). The hardness value of milled pure $\mathrm{Al}$ increased twice as much as that of unmilled pure Al. This improvement in hardness is related to the grain refinement of the Aluminum matrix due to high-energy ball milling. Although the higher hardness values of the nanocomposites are attributed to the in situ phases, the increasing trend of hardness in all nanocomposites is slower than that of pure Al. Therefore, it may be concluded that enhancing the mechanical properties of the extruded samples is mainly due to the grain refinement mechanism. 


\section{Conclusion}

In this study, aluminum nanocomposites containing 1,2 , and $4 \mathrm{wt} \%$ boron nitride nanoparticles were successfully fabricated by planetary ball milling of composite powders, cold compaction, and hot extrusion process. The results showed that the boron nitride nanoparticles had a remarkable influence on change in morphology and refinement of particle size in $\mathrm{Al}$ powder in the milling process as well as on the mechanical properties of the extruded samples. A high fraction of boron nitride nanoparticles dissolved resulting in formation of a solid solution in $\mathrm{Al}$ matrix after a milling time of $300 \mathrm{~min}$ at room temperature. This increased the work hardening rate of the composite powders in the milling process and caused an equiaxed shape in the $\mathrm{Al}$ powder along with creation of a nanocrystallite structure. In addition, in situ $\mathrm{AlN}$ and $\mathrm{AlB}_{2}$ phases were formed in a solid-state reaction with $\mathrm{Al}$ during sintering and hot extrusion processes. The milling process and boron nitride nanoparticle contents played an important role in improving the mechanical properties of the extruded samples. The results of mechanical tests of extruded milled and unmilled pure $\mathrm{Al}$ samples showed an increase around 100\% in hardness and tensile strength via the milling process. With the use of 1, 2, and $4 \mathrm{wt} \%$ nano-boron nitride, the hardness of the composites increased about 55, 70, and $90 \%$, respectively, compared to that of milled pure Al. The hardness of the composites also increased 230, 260, and $300 \%$, respectively, compared to that of unmilled pure $\mathrm{Al}$.

Acknowledgements This work was financially supported by the Shiraz University, Shiraz Iran, and "Iranian Nanotechnology Initiative" and research facilities of the Material Research School, Isfahan, Iran. This work was also supported by the research council office of Shiraz University through Grant Number 94-GR-ENG-15.

\section{References}

[1] D.B. Miracle, S.L. Donaldson, S.D. Henry, C. Moosbrugger, G.J. Anton, B.R. Sanders, N. Hrivnak, C. Terman, J. Kinson, K. Muldoon, ASM Handbook: Composites, vol. 21 (ASM International, Materials Park, 2001)

[2] P.M. Ajayan, L.S. Schadler, P.V. Braun, Nanocomposite Science and Technology, 1st edn. (Wiley-Vch, Weinheim, 2003), p. 14

[3] A. Abdollahi, A. Alizadeh, H.R. Baharvandi, Mater. Des. 55, 471 (2014)
[4] Z. Xia, Z. Li, C. Lu, B. Zhang, Y. Zhou, J. Alloys Compd. 399, 139 (2005)

[5] K. Lee, H. Sim, S. Heo, H. Yoo, S. Cho, H. Kwon, Compos. Part A Appl. Sci. Manuf. 33, 709 (2002)

[6] P. Shen, H. Fujii, K. Nogi, J. Mater. Sci. 42, 3564 (2007)

[7] Y. Du, S. Li, K. Zhang, K. Lu, Scr. Mater. 36, 7 (1997)

[8] Z.P. Xia, Z.Q. Li, J. Alloys Compd. 436, 170 (2007)

[9] I. Lonardelli, M. Zadra, G. Ischia, J.G. Barreiro, M. Bortolotti, J. Alloys Compd. 486, 653 (2009)

[10] I. Povstugar, A. Streletskii, D. Permenov, I. Kolbanev, S. Mudretsova, J. Alloys Compd. 483, 298 (2009)

[11] S. Nayak, S. Pabi, B. Murty, J. Alloys Compd. 492, 128 (2010)

[12] D. Zhou, F. Qiu, H. Wang, Q. Jiang, Acta Metall. Sin. (Eng. Lett.) 27, 798 (2014)

[13] E.O. Mokhnache, G. Wang, L. Geng, B. Kaveendran, L. Huang, Acta Metall. Sin. (Eng. Lett.) 27, 930 (2014)

[14] M. Galanty, P. Kazanowski, P. Kansuwan, W.Z. Misiolek, J. Mater. Process. Technol. 125-126, 491 (2002)

[15] P. Roberts, B. Ferguson, Int. Mater. Rev. 36, 62 (1991)

[16] M. Bauser, K. Siegert, Extrusion, 2nd edn. (Materials Park, ASM International, 2006), p. 290

[17] E.B. Tochaee, H.R.M. Hosseini, S.M.S. Reihani, Mater. Sci. Eng. A 658, 246 (2016)

[18] V.B. Prasad, B. Bhat, Y. Mahajan, P. Ramakrishnan, Mater. Manuf. Process. 16, 841 (2001)

[19] B. Avitzur, Metal Forming, Processes and Analysis, 1st edn. (McGraw-Hill, New York, 1968), p. 165

[20] K. Tavighi, M. Emamy, A.R. Emami, Mater. Des. 46, 598 (2013)

[21] A. Mohamed, A. Samuel, F. Samuel, H. Doty, Mater. Des. 30, 3943 (2009)

[22] K. Firestein, S. Corthay, A. Steinman, A. Matveev, A. Kovalskii, I. Sukhorukova, D. Golberg, D. Shtansky, Mater. Sci. Eng. A 681, 1 (2017)

[23] L.A. Dobrzański, A. Włodarczyk, M. Adamiak, J. Mater. Process. Technol. 175, 186 (2006)

[24] K.L. Firestein, A.E. Steinman, I.S. Golovin, Mater. Sci. Eng. A 642, 104 (2015)

[25] Z.R. Hesabi, A. Simchi, S.M.S. Reihani, Mater. Sci. Eng. A 428, 159 (2006)

[26] P. Soni, Mechanical Alloying: Fundamentals and Applications, 1st edn. (Cambridge International Science Publishing, Cambridge, 2001), p. 36

[27] G.E. Dieter, Mechanical Metallurgy, 3rd edn. (McGraw-Hill, New York, 1976), p. 189

[28] A. Alizadeh, E. Taheri-Nassaj, Mater. Charact. 67, 119 (2012)

[29] R. Deaquino-Lara, E. Gutiérrez-Castañeda, I. Estrada-Guel, Mater. Des. 53, 1104 (2014)

[30] O. El-Kady, A. Fathy, Mater. Des. 54, 348 (2014)

[31] H.K.D.H. Bhadeshia, R.W.K. Honeycombe, Steels: Microstructure and Properties, 3rd edn. (Butterworth-Heinemann, Oxford, 2006), p. 31 